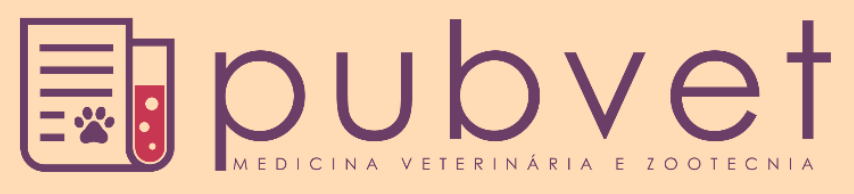

https://doi.org/10.31533/pubvet.v13n5a339.1-8

\title{
Características microbiológicas da água e das superfícies de bebedouros da Universidade Federal do Paraná - setor Palotina
}

\author{
Carolina Dias Rodrigues ${ }^{1}$, Ana Paula Perin ${ }^{1} \bullet$, Mallu Jagnow Sereno ${ }^{1}$, Kadigia Pegoraro $^{1 \bullet}$, \\ Thiago Henrique Bellé ${ }^{1}$, Emanoelli Aparecida Rodrigues dos $\operatorname{Santos}^{1}{ }^{\oplus}$, Vinicius Cunha \\ Barcellos $^{2} \odot$, Luciano dos Santos Bersot ${ }^{2 *}$ \\ ${ }^{I}$ Residente em inspeção de produtos de origem animal da Universidade Federal do Paraná(UFPR). Laboratório de Inspeção \\ e Controle de Qualidade de Alimentos e Água (LACOMA) - UFPR. Palotina -PR Brasil. \\ ${ }^{3}$ Professor da Universidade Federal do Paraná (UFPR). Laboratório de Inspeção e Controle de Qualidade de Alimentos e \\ Água (LACOMA) - UFPR. Palotina -PR Brasil. \\ *Autor para correspondência: lucianobersot@gmail.com
}

\begin{abstract}
Resumo. A água pode servir como veículo de diversos agentes patogênicos aos seres humanos e a contaminação de superfícies de equipamentos mal higienizados pode contribuir com baixa qualidade microbiológica da água. O objetivo dessa pesquisa foi avaliar a qualidade higiênico-sanitária das superfícies de bebedouros e da água para consumo da Universidade Federal do Paraná - Setor Palotina. Foi estabelecido um Procedimento Padrão de Higiene Operacional (PPHO) para a higienização dos bebedouros e aplicado um treinamento para o setor responsável pela atividade, para a padronização da higienização. Foram realizadas 392 avaliações de 24 bebedouros distribuídos pelo Setor, totalizando 784 análises microbiológicas de superfícies e 37 de água. Os parâmetros avaliados foram: contagem de micro-organismos aeróbios mesófilos e pesquisa de coliformes totais, termotolerantes e Escherichia coli. Todos os bebedouros (100\%) apresentaram contagens de micro-organismos aeróbios mesófilos superiores a $30 \mathrm{UFC} / \mathrm{cm}^{2}$ em pelo menos uma das avaliações realizadas. Dos 24 bebedouros, $17(70,8 \%)$ apresentaram coliformes totais, sete $(33,3 \%)$ apresentaram coliformes termotolerantes e em seis $(25 \%)$ foi verificada a presença de Escherichia coli. Das amostras de água, $31(83,8 \%)$ estavam adequadas para o consumo. Todos os bebedouros apresentaram-se inadequados para a utilização, no entanto a qualidade microbiológica da água não pareceu ter sido afetada. Os resultados podem ser reflexos do grande fluxo de utilização dos equipamentos, bem como da proximidade com instalações sanitárias. Por isso atividades de monitoramento higiênico-sanitária da água e dos bebedouros e trabalhos contínuos de treinamento e verificação são importantes.
\end{abstract}

Palavras-chave: higienização, indicadores, patógenos, saúde pública

\section{Microbiological characteristics of the water and surfaces of drinking fountains of the Federal University of Paraná - Palotina sector}

Abstract. Water can serve as a vehicle for several pathogens to humans and the contamination of poorly sanitized equipment surfaces can contribute to poor microbiological quality of water. The aim of this research was to assess the hygienicsanitary quality of drinking water and drinking fountain surfaces of the Federal University of Paraná - Sector Palotina. A Standard Operating Hygiene Procedure (PPHO) was established for the hygiene of drinking fountains and training was applied to the sector responsible for the hygienization standardization. There were 392 evaluations of 24 drinkers distributed throughout the Sector, totaling 784 microbiological analyzes of 
surfaces and 37 of water. The evaluated parameters were: count of aerobic mesophilic microorganisms and total coliform, thermotolerant and Escherichia coli. All drinkers $(100 \%)$ had mesophilic aerobic microorganisms counts above $30 \mathrm{CFU} / \mathrm{cm}^{2}$ in at least one of the evaluations performed. Of the 24 drinkers, 17 (70.8\%) had total coliforms, seven (33.3\%) had thermotolerant coliforms and in six (25\%) the presence of Escherichia coli was verified. Of the water samples, $31(83.8 \%)$ were adequate for consumption. All drinking fountains were unsuitable for use; however the microbiological quality of the water did not appear to have been affected. The results can be a reflection of the great flow of use of the equipment, as well as the proximity to sanitary facilities. Therefore hygienesanitary monitoring activities of water and drinking fountains and continuous training and verification work are important.

Key words: hygiene, indicators, pathogens, public health

\section{Características microbiológicas del agua y de las superficies de bebederos en la Universidad Federal de Paraná - sector Palotina}

Resumen. El agua puede servir como vehículo de diversos agentes patógenos a los seres humanos y la contaminación de superficies de equipos mal higienizados puede contribuir con baja calidad microbiológica del agua. El objetivo de esta investigación fue evaluar la calidad higiénico-sanitaria de las superficies de bebederos y del agua para consumo de la Universidad Federal de Paraná - Sector Palotina. Se estableció un Procedimiento Estándar de Higiene Operativa (PPHO) para la higienización de los bebederos y aplicado un entrenamiento para el sector responsable de la actividad, para la estandarización de la higienización. Se realizaron 392 evaluaciones de 24 bebederos distribuidos por el Sector, totalizando 784 análisis microbiológicos de superficies y 37 de agua. Los parámetros evaluados fueron: conteo de microorganismos aerobios mesófilos e investigación de coliformes totales, termotolerantes y Escherichia coli. Todos los bebederos (100\%) presentaron recuentos de microorganismos aerobios mesófilos superiores a $30 \mathrm{UFC} / \mathrm{cm} 2$ en al menos una de las evaluaciones realizadas. De los 24 bebederos, $17(70,8 \%)$ presentaron coliformes totales, siete $(33,3 \%)$ presentaron coliformes termotolerantes y en seis (25\%) se verificó la presencia de Escherichia coli. De las muestras de agua, $31(83,8 \%)$ eran adecuadas para el consumo. Todos los bebederos se presentaron inadecuados para el uso, pero la calidad microbiológica del agua no pareció haber sido afectada. Los resultados pueden ser reflejos del gran flujo de utilización de los equipos, así como de la proximidad con instalaciones sanitarias. Por eso las actividades de monitoreo higiénico-sanitario del agua y de los bebederos y trabajos continuos de entrenamiento y verificación son importantes.

Palabras clave: higienización, indicadores, patógenos, salud pública

\section{Introdução}

A qualidade e a inocuidade da água são de fundamental importância para a saúde da população, já que ela pode servir como um veículo de patógenos de origem bacteriana, viral e parasitária, que causam as mais diversas enfermidades aos seres humanos e animais (Hlavsa et al., 2011). A ingestão é o principal mecanismo direto de veiculação desses micro-organismos pela água, entretanto, sua má distribuição também pode ser citada como um mecanismo, nesse caso indireto, já que pode resultar em quantidade insuficiente para ser empregada na higiene pessoal e de utensílios (Brasil, 2006).

Sendo assim, equipamentos de uso comum para distribuição de água, como bebedouros instalados em ambientes públicos, podem atuar como fontes de contaminação direta aos seres humanos através da água fornecida para o consumo, ou ainda como fonte indireta de contaminação, quando mal higienizados, devido ao contato entre o usuário e o equipamento, visto que em ambientes públicos eles são utilizados por pessoas com hábitos higiênicos distintos (Freitas et al., 2013). Sabendo-se do risco da veiculação hídrica de patógenos, a qualidade microbiológica da água, mesmo tratada, e as condições higiênico-sanitárias dos sistemas de distribuição devem ser frequentemente verificadas (Brasil, 2017). 
A detecção de micro-organismos patogênicos na água na maioria das vezes é cara e laboriosa, visto a diversidade de patógenos que devem ser pesquisados, tornando-se inaplicável para fins de monitoramento ou verificação de rotina (Brasil, 2014). Dessa forma, uma das estratégias para o controle da qualidade microbiológica da água é a avaliação da presença dos chamados micro-organismos indicadores, que são facilmente identificáveis e cuja ocorrência aponta o risco da presença de microorganismos patogênicos e reflete as condições higiênicas (Brasil, 2006 e CETESB, 2007). Os mais importantes micro-organismos indicadores pesquisados são os do grupo coliformes e os aeróbios mesófílos (Brasil, 2006).

A Universidade Federal do Paraná - Setor Palotina é um ambiente público, onde podem circular pessoas das mais variadas faixas etárias, de hábitos higiênicos distintos, bem como pessoas imuno comprometidas. Sendo assim, torna-se necessária a implantação de ferramentas para o controle da qualidade higiênico-sanitária, tanto das superfícies dos bebedouros quanto da água consumida, para que estes locais ofereçam menos riscos à saúde dos funcionários, alunos e visitantes.

Nesse sentido, o Laboratório de Inspeção e Controle de Qualidade de Alimentos e Água (LACOMA), da UFPR, estabeleceu um Procedimento Padronizado de Higiene Operacional (PPHO) para higienização superficial dos bebedouros, e forneceu um treinamento para o setor responsável pela higienização como forma de padronizar a metodologia de limpeza destes equipamentos. Também estabeleceu um plano mensal de amostragem das superfícies dos bebedouros e da água utilizada para o consumo, com o objetivo de avaliar a eficiência do PPHO implantado.

\section{Material e métodos}

Esta pesquisa foi realizada entre abril de 2014 e dezembro de 2015. Inicialmente, os funcionários responsáveis pela higienização do setor receberam treinamento teórico-prático para implementação do PPHO, que estabeleceu passo-a-passo as etapas de higienização diária dos bebedouros. Para a execução do PPHO, os funcionários utilizavam luvas e utensílios exclusivos para essa finalidade. As superfícies (bandeja e acionadores de água) eram friccionadas com esponja e detergente neutro e, após a remoção das sujidades superficiais, a desinfecção era realizada com álcool $70 \%$.

Os parâmetros utilizados para determinar a eficiência do PPHO e da qualidade da água foram: contagens de micro-organismos aeróbios mesófilos e pesquisa de coliformes totais, termo tolerantes e Escherichia coli. Para tal, foram coletados swabs da superfície do acionador de água (superfície A) e da bandeja (superfície B) dos bebedouros, que foram acondicionados em Solução Salina estéril 0,85\%. A água dos bebedouros foi coletada assepticamente em frascos estéreis contendo $0,1 \mathrm{~mL}$ de Tiossulfato de Sódio $\left(\mathrm{Na}_{2} \mathrm{~S}_{2} \mathrm{O}_{3}\right)$ a $10 \%$ para cada $100 \mathrm{~mL}$ de água coletada. As amostras foram encaminhadas em caixa isotérmicas ao LACOMA.

Ao todo foram coletadas amostras de 24 bebedouros distribuídos pelo Campus da UFPR - Setor Palotina. As amostragens foram realizadas mensalmente durante 20 meses de acompanhamento. No total foram realizadas 392 avaliações de bebedouros, compreendendo 784 análises microbiológicas, descartando-se as vezes em que os equipamentos se encontravam em manutenção. A água para consumo foi coletada quinzenalmente durante o período de avaliação, o que resultou em 37 análises de água realizadas. A escolha dos bebedouros para a coleta de água foi realizada aleatoriamente.

Para contagem de micro-organismos aeróbios mesófilos das superfícies e da água, alíquotas de $1 \mathrm{~mL}$ das diluições seriadas das amostras foram semeados em placas com Ágar Padrão para Contagem (PCA) e incubados a $35^{\circ} \mathrm{C} \pm 1 / 48 \pm 2 \mathrm{~h}$. Após a incubação, foi realizada a contagem das Unidades Formadoras de Colônia (UFC).

Para a determinação de coliformes nas superfícies, uma alíquota de $9,0 \mathrm{~mL}$ da solução salina $0,85 \%$ foi inoculada em caldo Lauril Triptose (LST) em dupla concentração, que foi incubado a $35^{\circ} \mathrm{C} \pm 1 / 48 \pm 2 \mathrm{~h}$. Nas amostras de água, a detecção de coliformes foi realizada pelo método do Número Mais Provável (NMP), no qual dez alíquotas de $10 \mathrm{~mL}$ da água foram inoculadas em 10 tubos contendo caldo LST em dupla concentração. Em ambos os casos, a partir dos tubos de LST positivos, foi realizada a confirmação para coliformes totais em caldo Bile Verde Brilhante $2 \%\left(35^{\circ} \mathrm{C} / 48 \mathrm{~h}\right)$, coliformes termotolerantes em caldo EC $\left(44,5^{\circ} \mathrm{C} / 48 \mathrm{~h}\right)$ e identificaçao de E.coli, conforme metodologia recomendada pela (APHA, 2014). 
Os resultados das análises realizadas para micro-organismos aeróbios mesófilos nas superfícies dos bebedouros foram comparados aos padrões de contagem determinados pela American Public Health Association (APHA, 2014) para superfícies de processamento de alimentos $\left(<30 \mathrm{UFC} / \mathrm{cm}^{2}\right)$. Desta forma, foram considerados como conformes quando inferiores a este limite, ou não conformes quando superiores. A presença de coliformes totais, termotolerantes e E. coli nas superfícies dos bebedouros foi considerada como não conformidade. As amostras de água foram consideras como conformes ou não conformes de acordo com os padrões de potabilidade estabelecidos pela Portaria de consolidação ${ }^{\circ}$ 5/2017 (Brasil, 2017).

\section{Resultados e discussão}

Todos os bebedouros apresentaram contagens de micro-organismos aeróbios mesófilos superiores à $30 \mathrm{UFC} / \mathrm{cm}^{2}$, em pelo menos uma das superfícies amostradas. Além disso, 17 equipamentos $(70,8 \%)$ apresentaram coliformes totais em pelo menos uma avaliação. Dessa maneira, todos os bebedouros apresentaram-se inadequados para o uso durante o período amostral para pelo menos um parâmetro avaliado (Tabela 1).

Tabela 1. Conformidade das superfícies amostrais para ausência de coliformes totais e contagem de aeróbios mesófilos de acordo com os limites estabelecidos. Universidade Federal do Paraná, Setor Palotina, 2016

\begin{tabular}{|c|c|c|c|c|c|}
\hline \multirow{2}{*}{$\begin{array}{l}\text { Número do } \\
\text { Bebedouro }\end{array}$} & \multicolumn{2}{|c|}{ Coliformes totais ${ }^{1}$} & \multicolumn{2}{|c|}{ Aeróbios mesófilos ${ }^{2}$} & \multirow{2}{*}{$\begin{array}{l}\text { Conformidade do } \\
\text { bebedouro }\end{array}$} \\
\hline & Conformidade & Amostras $\mathrm{NC} / \mathrm{n}^{3}$ & Conformidade & Amostras $\mathrm{NC} / \mathrm{n}^{3}$ & \\
\hline 1 & $\mathrm{C}$ & $0 / 20$ & $\mathrm{NC}$ & $18 / 20$ & $\mathrm{NC}$ \\
\hline 2 & $\mathrm{NC}$ & $6 / 20$ & $\mathrm{NC}$ & $19 / 20$ & $\mathrm{NC}$ \\
\hline 3 & $\mathrm{NC}$ & $1 / 20$ & $\mathrm{NC}$ & $16 / 20$ & $\mathrm{NC}$ \\
\hline 4 & $\mathrm{NC}$ & $2 / 20$ & $\mathrm{NC}$ & $20 / 20$ & $\mathrm{NC}$ \\
\hline 5 & $\mathrm{NC}$ & $3 / 20$ & $\mathrm{NC}$ & $20 / 20$ & $\mathrm{NC}$ \\
\hline 6 & $\mathrm{C}$ & $0 / 20$ & $\mathrm{NC}$ & $19 / 20$ & $\mathrm{NC}$ \\
\hline 7 & $\mathrm{NC}$ & $6 / 18$ & $\mathrm{NC}$ & $16 / 18$ & $\mathrm{NC}$ \\
\hline 8 & $\mathrm{C}$ & $0 / 19$ & $\mathrm{NC}$ & $18 / 19$ & $\mathrm{NC}$ \\
\hline 9 & $\mathrm{NC}$ & $1 / 20$ & $\mathrm{NC}$ & $19 / 20$ & $\mathrm{NC}$ \\
\hline 10 & $\mathrm{NC}$ & $1 / 13$ & $\mathrm{NC}$ & $13 / 13$ & $\mathrm{NC}$ \\
\hline 11 & $\mathrm{NC}$ & $2 / 18$ & $\mathrm{NC}$ & $17 / 18$ & $\mathrm{NC}$ \\
\hline 12 & $\mathrm{C}$ & $0 / 8$ & $\mathrm{NC}$ & $8 / 8$ & $\mathrm{NC}$ \\
\hline 13 & $\mathrm{NC}$ & $2 / 20$ & $\mathrm{NC}$ & $18 / 20$ & $\mathrm{NC}$ \\
\hline 14 & $\mathrm{NC}$ & $4 / 20$ & $\mathrm{NC}$ & $19 / 20$ & $\mathrm{NC}$ \\
\hline 15 & $\mathrm{NC}$ & $3 / 20$ & $\mathrm{NC}$ & $18 / 20$ & $\mathrm{NC}$ \\
\hline 16 & $\mathrm{NC}$ & $1 / 20$ & $\mathrm{NC}$ & $18 / 20$ & $\mathrm{NC}$ \\
\hline 17 & $\mathrm{NC}$ & $2 / 20$ & $\mathrm{NC}$ & $18 / 20$ & $\mathrm{NC}$ \\
\hline 18 & $\mathrm{NC}$ & $1 / 20$ & $\mathrm{NC}$ & $17 / 20$ & $\mathrm{NC}$ \\
\hline 19 & $\mathrm{C}$ & $0 / 6$ & $\mathrm{NC}$ & $6 / 6$ & $\mathrm{NC}$ \\
\hline 20 & $\mathrm{C}$ & $0 / 3$ & $\mathrm{NC}$ & $3 / 3$ & $\mathrm{NC}$ \\
\hline 21 & $\mathrm{NC}$ & $5 / 11$ & $\mathrm{NC}$ & $10 / 11$ & $\mathrm{NC}$ \\
\hline 22 & $\mathrm{NC}$ & $3 / 12$ & $\mathrm{NC}$ & $12 / 12$ & $\mathrm{NC}$ \\
\hline 23 & $\mathrm{C}$ & $0 / 12$ & $\mathrm{NC}$ & $12 / 12$ & $\mathrm{NC}$ \\
\hline 24 & $\mathrm{NC}$ & $3 / 12$ & $\mathrm{NC}$ & $12 / 12$ & $\mathrm{NC}$ \\
\hline
\end{tabular}

$\mathrm{C}=$ conforme $\mathrm{NC}=$ não conforme $\mathrm{n}=$ número total de amostras. ${ }^{1}$ Conformidade: ausência de coliformes totais/não conformidade: presença de coliformes totais. ${ }^{2}$ Limite aceitável para contagem de aeróbios mesófilos em superfícies de processamento de alimentos, de acordo com a APHA (2001), é de 30UFC/ $\mathrm{cm}^{2}$. ${ }^{3}$ Número de amostras não conforme sobre o número total de amostras avaliadas.

Para microrgnismos aerobios mesófilos, a superfície A de amostragem foi a que apresentou as maiores medianas de contagens, as quais variaram entre $9,5 \times 10^{1} \mathrm{UFC} / \mathrm{cm}^{2}$ e $4,7 \times 10^{4} \mathrm{UFC} / \mathrm{cm}^{2}$, de foma que todos os bebedouros apresentaram-se não conformes para esse parâmetro. Na superfície B, 14 bebedouros $(58,3 \%)$ apresentaram contagens de aeróbios mesófilos superiores ao limite máximo 
estabelecido, estando em não conformidade com os parâmetros determinados, enquanto 10 (41,7\%) apresentaram contagens inferiores, estando em conformidade (Tabela 2).

Tabela 2. Mediana da contagem de micro-organismos aeróbios mesófilos nas superfícies A e B de amostragem e sua conformidade com o limite de contagem $\left(<30 \mathrm{UFC} / \mathrm{cm}^{2}\right)$ estabelecido pela APHA (2001) para superfícies de processamento de alimentos. Universidade Federal do Paraná, Setor Palotina, 2016.

\begin{tabular}{|c|c|c|c|c|}
\hline \multirow{2}{*}{ Número do Bebedouro } & \multicolumn{4}{|c|}{ Contagem de aeróbios mesófilos nas superfícies amostradas } \\
\hline & Superfície $\mathrm{A}^{1}$ & Conformidade $^{2}$ & Superfície $\mathrm{B}^{1}$ & Conformidade $^{2}$ \\
\hline 1 & $7,8 \times 10^{2}$ & $\mathrm{NC}$ & $1,2 \times 10^{1}$ & $\mathrm{C}$ \\
\hline 2 & $1,3 \times 10^{2}$ & $\mathrm{NC}$ & $2,3 \times 10^{1}$ & $\mathrm{C}$ \\
\hline 3 & $2,9 \times 10^{2}$ & $\mathrm{NC}$ & 7 & $\mathrm{C}$ \\
\hline 4 & $4,7 \times 10^{4}$ & $\mathrm{NC}$ & $3,8 \times 10^{1}$ & $\mathrm{NC}$ \\
\hline 5 & $2,1 \times 10^{4}$ & $\mathrm{NC}$ & $3,3 \times 10^{1}$ & $\mathrm{NC}$ \\
\hline 6 & $8,8 \times 10^{3}$ & $\mathrm{NC}$ & $1,5 \times 10^{1}$ & $\mathrm{C}$ \\
\hline 7 & $2,0 \times 10^{2}$ & $\mathrm{NC}$ & $6,8 \times 10^{1}$ & $\mathrm{NC}$ \\
\hline 8 & $2,8 \times 10^{2}$ & $\mathrm{NC}$ & $2,5 \times 10^{1}$ & $\mathrm{C}$ \\
\hline 9 & $1,8 \times 10^{2}$ & $\mathrm{NC}$ & $1,40 \times 10^{1}$ & $\mathrm{NC}$ \\
\hline 10 & $3,9 \times 10^{2}$ & $\mathrm{NC}$ & 6 & $\mathrm{C}$ \\
\hline 11 & $1,1 \times 10^{4}$ & $\mathrm{NC}$ & $9,5 \times 10^{1}$ & $\mathrm{NC}$ \\
\hline 12 & $6,4 \times 10^{3}$ & $\mathrm{NC}$ & 5 & $\mathrm{C}$ \\
\hline 13 & $5,5 \times 10^{2}$ & $\mathrm{NC}$ & $3,0 \times 10^{1}$ & $\mathrm{C}$ \\
\hline 14 & $1,4 \times 10^{3}$ & $\mathrm{NC}$ & $2,5 \times 10^{2}$ & $\mathrm{NC}$ \\
\hline 15 & $9,0 \times 10^{2}$ & $\mathrm{NC}$ & $7,0 \times 10^{1}$ & $\mathrm{NC}$ \\
\hline 16 & $8,0 \times 10^{2}$ & $\mathrm{NC}$ & $5,6 \times 10^{1}$ & $\mathrm{NC}$ \\
\hline 17 & $6,3 \times 10^{2}$ & $\mathrm{NC}$ & $5,3 \times 10^{1}$ & $\mathrm{NC}$ \\
\hline 18 & $9,5 \times 10^{1}$ & $\mathrm{NC}$ & $1,9 \times 10^{1}$ & $\mathrm{C}$ \\
\hline 19 & $1,0 \times 10^{2}$ & $\mathrm{NC}$ & $3,3 \times 10^{1}$ & $\mathrm{NC}$ \\
\hline 20 & $1,1 \times 10^{3}$ & $\mathrm{NC}$ & $2,4 \times 10^{1}$ & $\mathrm{C}$ \\
\hline 21 & $1,0 \times 10^{3}$ & $\mathrm{NC}$ & $2,4 \times 10^{2}$ & $\mathrm{NC}$ \\
\hline 22 & $6,0 \times 10^{2}$ & $\mathrm{NC}$ & $6,3 \times 10^{1}$ & $\mathrm{NC}$ \\
\hline 23 & $1,8 \times 10^{3}$ & $\mathrm{NC}$ & $1,1 \times 10^{2}$ & $\mathrm{NC}$ \\
\hline 24 & $1,2 \times 10^{3}$ & $\mathrm{NC}$ & $3,5 \times 10^{2}$ & $\mathrm{NC}$ \\
\hline
\end{tabular}

$\mathrm{C}=$ conformidade e $\mathrm{NC}=$ não conformidade. ${ }^{1}$ Mediana, calculada com base no número de amostragem de cada bebedouro, expressa em UFC/cm ${ }^{2} .{ }^{2}$ Limite aceitável para contagem de aeróbios mesófilos em superfícies de processamento de alimentos, de acordo com a APHA (2001), é de 30UFC/ $\mathrm{cm}^{2}$.

As bactérias aeróbias mesófilas estão presentes em todos os tipos de água, nos alimentos, no solo, na vegetação e no ar. Sua contagem pode fornecer uma indicação geral sobre a qualidade microbiológica da água e pode demonstrar alterações causadas devido ao armazenamento, eficiência dos métodos de tratamento, integridade e limpeza do sistema de distribuição e formação de biofilmes (WHO, 2008).

A superfície A de amostragem pode ser considerada o local de maior contato entre os usuários e o equipamento, pois precisa necessariamente ser pressionada com os dedos para a ejeção da água. É sabido que a pele, inclusive das mãos, tem a capacidade de abrigar diversos micro-organismos e de transferilos de uma superfície para a outra através do contato direto (Larson, 1995). Reconhecidamente, a prática da higienização das mãos reduz significativamente a transmissão desses micro-organismos e, consequentemente, diminui a incidência de infecções (Pratt et al., 2007). Tendo em vista os diferentes hábitos de higiene dos usuários de bebedouros públicos da UFPR, é possível considerar que a má higienização das mãos também esteja relacionada com o elevado grau de contaminação nessas superfícies, principalmente pelo fato dos bebedouros amostrados estarem localizados próximos às saídas de instalações sanitárias, como descrito em trabalho desenvolvido por Freitas et al. (2013).

Outro grupo de micro-organismos que podem ser utilizados como indicadores de contaminação ambiental são os coliformes, que podem se multiplicar em água e biofilmes, e demonstram uma 
avaliação geral da eficiência da limpeza e integridade dos sistemas de distribuição e presença de biofilmes (SCA, 2002, WHO, 2008).

Neste estudo, dos 24 bebedouros avaliados, 17 (70,8\%) apresentaram coliformes totais em pelo menos uma avaliação. A presença de coliformes totais foi verificada na superfície B em 16 bebedouros (67\%), enquanto na superfície A, a sua presença foi identificada em 10 bebedouros (41,7\%) (Tabela 3 ).

Tabela 3. Superfícies A e B dos bebedouros não conformes para coliformes totais durante o período amostral. Universidade Federal do Paraná, Setor Palotina, 2016.

\begin{tabular}{|c|c|c|c|c|}
\hline \multirow{3}{*}{ Número do Bebedouro } & \multicolumn{4}{|c|}{ Coliformes totais } \\
\hline & \multicolumn{2}{|c|}{ Superfície A } & \multicolumn{2}{|c|}{ Superfície B } \\
\hline & $\mathrm{C} / \mathrm{NC}^{1}$ & Amostras $\mathrm{NC} / \mathrm{n}^{3}$ & $\mathrm{C} / \mathrm{NC}^{1}$ & Amostras $\mathrm{NC} / \mathrm{n}^{3}$ \\
\hline 2 & $\mathrm{NC}$ & $3 / 20$ & $\mathrm{NC}$ & $3 / 20$ \\
\hline 3 & $\mathrm{NC}$ & $1 / 20$ & $\mathrm{NC}$ & $1 / 20$ \\
\hline 4 & $\mathrm{NC}$ & $1 / 20$ & $\mathrm{NC}$ & $1 / 20$ \\
\hline 5 & $\mathrm{C}$ & $0 / 20$ & $\mathrm{NC}$ & $3 / 20$ \\
\hline 7 & $\mathrm{C}$ & $0 / 18$ & $\mathrm{NC}$ & $6 / 18$ \\
\hline 9 & $\mathrm{C}$ & $0 / 20$ & $\mathrm{NC}$ & $1 / 20$ \\
\hline 10 & $\mathrm{NC}$ & $1 / 13$ & $\mathrm{NC}$ & $1 / 13$ \\
\hline 11 & $\mathrm{NC}$ & $1 / 20$ & $\mathrm{NC}$ & $1 / 20$ \\
\hline 13 & $\mathrm{NC}$ & $2 / 20$ & $\mathrm{C}$ & $0 / 20$ \\
\hline 14 & $\mathrm{NC}$ & $3 / 20$ & $\mathrm{NC}$ & $2 / 20$ \\
\hline 15 & $\mathrm{C}$ & $0 / 20$ & $\mathrm{NC}$ & $3 / 20$ \\
\hline 16 & $\mathrm{C}$ & $0 / 20$ & $\mathrm{NC}$ & $1 / 20$ \\
\hline 17 & $\mathrm{C}$ & $0 / 20$ & $\mathrm{NC}$ & $2 / 20$ \\
\hline 18 & $\mathrm{C}$ & $0 / 20$ & $\mathrm{NC}$ & $1 / 20$ \\
\hline 21 & $\mathrm{NC}$ & $4 / 11$ & $\mathrm{NC}$ & $2 / 11$ \\
\hline 22 & $\mathrm{NC}$ & $3 / 12$ & $\mathrm{NC}$ & $1 / 12$ \\
\hline 24 & $\mathrm{NC}$ & $1 / 12$ & $\mathrm{NC}$ & $3 / 12$ \\
\hline
\end{tabular}

$\mathrm{C}=$ conformidade $\mathrm{NC}=$ não conformidade $\mathrm{n}=$ número total de amostras. ${ }^{1}$ Conformidade: ausência de coliformes totais/não conformidade: presença de coliformes totais. ${ }^{3}$ Número de amostras não conforme sobre o número total de amostras avaliadas.

Dos 17 equipamentos $(70,8 \%)$ que apresentaram coliformes totais, sete $(33,3 \%)$ apresentaram coliformes termos tolerantes e em seis $(25 \%)$ foi confirmada a presença de Escherichia coli em pelo menos uma das avaliações. Para coliformes termos tolerantes, nas superfícies A e B de amostragem, três $(12,5 \%)$ e seis $(25 \%)$ bebedouros, respectivamente, estiveram não conformes (Tabela 4).

Tabela 4. Conformidade das superfícies A e B dos bebedouros avaliados para coliformes termotolerantes e E. coli durante o período amostral. Universidade Federal do Paraná, Setor Palotina, 2016.

\begin{tabular}{|c|c|c|c|c|c|c|c|c|}
\hline \multirow{3}{*}{$\begin{array}{l}\text { Número do } \\
\text { Bebedouro }\end{array}$} & \multicolumn{4}{|c|}{ Coliformes termotolerantes } & \multicolumn{4}{|c|}{ E.coli } \\
\hline & \multicolumn{2}{|c|}{ Superfície A } & \multicolumn{2}{|c|}{ Superfície B } & \multicolumn{2}{|c|}{ Superfície A } & \multicolumn{2}{|c|}{ Superfície B } \\
\hline & $\mathrm{C} / \mathrm{NC}^{1}$ & $\begin{array}{c}\text { Amostras } \\
\mathrm{NC} / \mathrm{n}^{3}\end{array}$ & $\mathrm{C} / \mathrm{NC}^{1}$ & $\begin{array}{c}\text { Amostras } \\
\mathrm{NC} / \mathrm{n}^{3}\end{array}$ & $\mathrm{C} / \mathrm{NC}^{1}$ & $\begin{array}{c}\text { Amostras } \\
\mathrm{NC} / \mathrm{n}^{3}\end{array}$ & $\mathrm{C} / \mathrm{NC}^{1}$ & Amostras $\mathrm{NCn}^{3}$ \\
\hline 2 & $\mathrm{NC}$ & $1 / 20$ & $\mathrm{NC}$ & $1 / 20$ & $\mathrm{NC}$ & $1 / 20$ & $\mathrm{NC}$ & $1 / 20$ \\
\hline 5 & $\mathrm{C}$ & $0 / 20$ & $\mathrm{NC}$ & $1 / 20$ & $\mathrm{C}$ & $0 / 20$ & $\mathrm{NC}$ & $1 / 20$ \\
\hline 7 & $\mathrm{C}$ & $0 / 18$ & $\mathrm{NC}$ & $1 / 18$ & $\mathrm{C}$ & $0 / 18$ & $\mathrm{NC}$ & $1 / 18$ \\
\hline 11 & $\mathrm{NC}$ & $1 / 20$ & $\mathrm{C}$ & $0 / 20$ & $\mathrm{NC}$ & $1 / 20$ & $\mathrm{C}$ & $0 / 20$ \\
\hline 15 & $\mathrm{C}$ & $0 / 20$ & $\mathrm{NC}$ & $1 / 20$ & $\mathrm{C}$ & $0 / 20$ & $\mathrm{NC}$ & $1 / 20$ \\
\hline 22 & $\mathrm{C}$ & $0 / 12$ & $\mathrm{NC}$ & $1 / 12$ & $\mathrm{C}$ & $0 / 12$ & $\mathrm{NC}$ & $1 / 12$ \\
\hline 24 & $\mathrm{NC}$ & $1 / 12$ & $\mathrm{NC}$ & $1 / 12$ & $\mathrm{C}$ & $0 / 12$ & $\mathrm{C}$ & $0 / 12$ \\
\hline
\end{tabular}

$\overline{\mathrm{C}}=$ conformidade $\mathrm{NC}=$ não conformidade $\mathrm{n}=$ número de amostras. ${ }^{1}$ Conformidade: ausência de coliformes totais/não conformidade: presença de coliformes totais. ${ }^{3}$ Número de amostras não conforme sobre o número total de amostras avaliadas. 
A presença de coliformes termos tolerantes nas superfícies e água pode estar relacionada à presença tanto de micro-organismos da espécie Escherichia coli, que tem como habitat primário o intestino de humanos e animais, quanto àqueles encontrados em vegetais e solo, como Klebsiella e Enterobacter (Silva et al., 2010). Nesta pesquisa, em seis bebedouros amostrados (25\%) foi identificada a bactéria E. coli, representando $85,7 \%$ das amostras nas quais houve presença de coliformes termo tolerantes (Tabela 4).

E. coli é a bactéria predominante do subgrupo dos coliformes termo tolerantes e a única desse grupo cujo habitat exclusivo é o trato intestinal de humanos e de animais de sangue quente (Silva et al., 2010). Sua presença está relacionada principalmente com indícios de contaminação fecal, o que caracteriza falhas no processo de higienização dos equipamentos e do tratamento da água (Brasil, 2006). Existem também cepas de E. coli que possuem características enterotoxigênicas, as quais são extremamente importantes para a saúde pública, pois estão intimamente relacionadas a síndromes diarreicas graves (Koneman et al., 2001).

Quanto às amostras de água, de acordo com o Ministério da Saúde, algumas características fisícoquímicas e microbiológicas devem ser respeitadas para a água ser considerada potável. Dentro das características microbiológicas necessárias, a água deve apresentar contagem de micro-organismos aeróbios mesófilos inferiores a 500UFC/mL e ausência de coliformes em $100 \mathrm{~mL}$ (Brasil, 2017). Neste estudo, das 37 amostras de água analisadas, $31(83,8 \%)$ apresentaram-se dentro dos padrões de potabilidade. Nenhuma das amostras avaliadas apresentou coliformes em $100 \mathrm{~mL}$, entretanto, as seis amostras $(16,2 \%)$ que estiveram fora dos padrões de potabilidade apresentaram contagens de microorganismos aeróbios mesófilos superiores a $500 \mathrm{UFC} / \mathrm{mL}$. As amostras de água que se apresentaram fora do padrão de portabilidade não puderam ser correlacionadas com os bebedouros que apresentaram maiores níveis de contaminação superficial, pois essas amostras de água foram coletadas de bebedouros que apresentaram menor frequência de contaminação por coliformes e contagens de aeróbios mesófilas mais baixas.

Em estudo conduzido por Waideman (2015) para avaliar a qualidade microbiológica da água de bebedouros em 45 escolas da rede pública de Curitiba, a autora observou que $11 \%$ das amostras coletadas apresentaram-se fora dos padrões de potabilidade. Zulpo et al. (2006), avaliando a qualidade microbiológica da água fornecida nos bebedouros da Universidade Estadual do Centro Oeste do Paraná, em Guarapuava - PR observaram que quatro $(8,5 \%)$ das 47 amostras analisadas estiveram fora dos padrões estabelecidos pela legislação, já que foram positivas para coliformes.

Por outro lado, Reis et al. (2012) ao avaliarem a qualidade microbiológica de águas de bebedouros coletadas em dois parques de Curitiba, observaram que 100\% das amostras analisadas apresentaramse dentro dos padrões de potabilidade. Resultados semelhantes foram observados por Seco et al. (2012), ao avaliarem a qualidade microbiológica de 19 amostras de água colhidas dos bebedouros da Universidade Estadual de Londrina. Ainda, Mello \& Resende (2015), ao analisarem a qualidade microbiológica da água dos bebedouros da Pontifícia Universidade Católica de Minas Gerais, Campus Betim, também obtiveram 100\% de conformidade das amostras.

\section{Conclusões}

Apesar das elevadas contagens de micro-organismos aeróbios mesófilos e da identificação de coliformes na maioria das amostras de superfície dos bebedouros, essa contaminação não pareceu interferir na qualidade da água, visto que $83,8 \%$ das amostras de água apresentaram-se dentro dos padrões de potabilidade, estando adequadas ao consumo humano. Não se pode indicar o motivo pelo qual todos os bebedouros apresentaram não conformidades microbiológicas mesmo com a adoção de $\mathrm{PPHO}$ e treinamento de funcionários, mas essas inconformidades podem estar relacionadas ao alto fluxo de usuários e a localização dos equipamentos, próximas de instalações sanitárias. Assim, os resultados mostram a importância da manutenção das atividades para monitoramento da qualidade higiênicosanitária da água e dos bebedouros e de trabalhos contínuos de treinamento e verificação, que devem ser desenvolvidos com o objetivo de manter a integridade e segurança desses equipamentos, além da adequação dos locais de instalação dos bebedouros em ambientes públicos a fim de evitar agravos à saúde dos usuários. 


\section{Referências bibliográficas}

APHA. (2014). Standard methods for the examination of water and wastewater (Vol. 20): American Public Health Association.

BRASIL. (2006). Ministério Da Saúde. Vigilância e Controle da Qualidade da Água para Consumo Humano. Secretaria de Vigilância em Saúde. Brasília: Ministério da Saúde, 212.

BRASIL. (2014). Ministério Da Saúde. Manual de Controle da Qualidade da Água para Técnicos que Trabalham em ETAS. Fundação Nacional de Saúde. Brasília: Funasa, 112.

BRASIL. (2017). Ministério da Saúde. Portaria de consolidação No 5, de 28 setembro de 2017. Consolidação das normas sobre as ações e os serviços de saúde do Sistema Único de Saúde. Diário Oficial [da] República Federativa do Brasil, Brasília, de 28 setembro de 2017.

CETESB. (2007). Companhia Ambiental do Estado de São Paulo. L5.214: Coliformes Totais: Determinação pela Técnica de Membrana Filtrante - método de ensaio. São Paulo, 31.

Freitas, L. L., Silva, K. C., Demarque, I. L. D. \& Agostinho, L., Fernandes, F. (2013). Quantificação microbiológica de bebedouros de escolas públicas em Muriaé (MG). Revista Científica da FAMINAS, 9(1):81-93.

Hlavsa, M. C., Roberts, V. A., Anderson, A. R., Hill, V. R., Kahler, A. M., Orr, M., . . Hilborn, E. D. (2011). Surveillance for waterborne disease outbreaks and other health events associated with recreational water-United States, 2007-2008. Morbidity Mortality Weekly Report, 60(12):1-32.

Koneman, E. W., Allen, S. D., Janda, W. M., Schreckenberger, P. C. \& Winn Junior, W. C. (2001). Diagnóstico Microbiológico: Texto e Atlas Colorido. Rio de Janeiro: Medsi, 1465. Rio de Janeiro, Brasil: Medsi.

Larson, E. L. (1995). APIC guidelines for handwashing and hand antisepsis in health care settings. American Journal of Infection Control, 23(4):251-269.

Mello, C. N. \& Resende, J. C. R. (2015). Analise microbiológica da água dos bebedouros da Pontifícia Universidade Católica de Minas Gerais campus Betim. Sinapse Múltipla, 4(1):16-28.

Pratt, R. J., Pellowe, C. M., Wilson, J. A., Loveday, H. P., Harper, P. J., Jones, S. R. L. J., . . Wilcox, M. H. (2007). epic2: National evidence-based guidelines for preventing healthcare-associated infections in NHS hospitals in England. Journal of Hospital Infection, 65S1-S59.

Reis, F., Abrahão, W. M. \& Murakami, F. S. (2012). Avaliação da qualidade microbiológica de águas e superfícies de bebedouros de parques de Curitiba-PR. Visão Acadêmica, 13(1):55-70.

SCA. (2002). Standing Committee of Analysts. The microbiology of drinking water: water quality and public health - part 1. Nottingham: Environment Agency.

Seco, B. M. S., Burgos, T. N. \& Pelayo, J. S. (2012). Avaliação bacteriológica das águas de bebedouros do campus da Universidade Estadual de Londrina-PR. Semina: Ciências Biológicas e da Saúde, 33(2):193-200.

Silva, N., Junqueira, V. C. A., Siveira, N. F. A., Taniwaki, M. H., Santos, R. F. S. \& Gomes, R. A. R. (2010). Manual de métodos de análises microbiológica de alimentos e água. São Paulo, Brasil: Livraria Varela.

Zulpo, D. L., Peretti, J., Ono, L. M. \& Garcia, J. L. (2006). Avaliação microbiológica da água consumida nos bebedouros da Universidade Estadual do Centro-Oeste, Guarapuava, Paraná, Brasil. Semina: Ciências Agrárias, 27(1):107-110.

Waideman, M. A. (2015) Qualidade de água de torneira e de bebedouro em escolas públicas estaduais de um município do estado do Paraná. (Dissertação de Mestrado). Universidade Federal do Paraná, Curitiba.

WHO. (2008). World Health Organzation. Guidelines for Drinking-Water Quality. Geneva.

Recebido: 20 de abril, 2019.

Aprovado: 22 de maio, 2019.

Publicado: 7 de junho, 2019.

Licenciamento: Este artigo é publicado na modalidade Acesso Aberto sob a licença Creative Commons Atribuição 4.0 (CC-BY 4.0), a qual permite uso irrestrito, distribuição, reprodução em qualquer meio, desde que o autor e a fonte sejam devidamente creditados. 